\title{
What services and supports are needed to enable trauma survivors to rebuild their lives? Implications of a systematic case study of cognitive therapy with a township adolescent girl with PTSD following rape
}

\author{
Charmaine Payne \\ Department of Psychology, Rhodes University \\ David Edwards \\ Department of Psychology, Rhodes University \\ E-mail: d.edwards@ru.ac.za
}

\begin{abstract}
This systematic clinical case study describes the psychological assessment and treatment with cognitive therapy of Zanele, a Xhosa-speaking adolescent rape survivor with major depressive disorder and posttraumatic stress disorder (PTSD). A case narrative was developed to document the main features of the therapy process and progress was monitored using scales measuring symptoms of depression and PTSD. The narrative documents the operation in a local context of factors that maintain PTSD that have been identified in the international literature and, with the self-report scales, provides evidence for Zanele's recovery from PTSD and the transportability to this context of an evidence-based psychological treatment. The narrative also documents the lack of safety for young women and girls in a South African township as well as significant limitations in the professional services available: in this case, Zanele was infected with HIV and other sexually transmitted diseases but medical management had not been followed through, and criminal charges against the rapist were dropped, and dropped again even after he had committed another rape on a six-year-old girl. This provides a basis for examining the complementary roles that can be played by psychologists and other professionals in empowering trauma survivors to regain a sense of dignity and control over their lives.
\end{abstract}

\section{CASE CONTEXT AND METHOD}

Over 50000 rapes of women and girls are reported to the South African Police Services (2005) every year. Reported rapes are, however, only the "tip of the iceberg;" this figure massively underestimates the total number of females who are forced to have sex against their will and adolescent females are particularly vulnerable (Jewkes \& Abrahams 2002: 1233). Rape survivors commonly suffer from depression and post-traumatic stress disorder which may be chronic if psychological treatment is not provided (Foa \& Rothbaum 1998). This case study describes the psychological assessment and treatment of Zanele (pseudonym), a 15-year-old Xhosaspeaking adolescent who had been raped on two separate occasions while walking though the township near her home. As a result, she was experiencing severe difficulties at school, where on several occasions she had run out of the classroom in a panic, and had largely withdrawn from normal social activities. When assessed, Zanele had severe posttraumatic stress disorder (PTSD) and was also severely depressed.

\section{Rationale for selecting this client for study}

Clinical case studies contribute to the scientific literature because they provide documentation of psychological assessment and the application of psychological interventions in naturalistic settings. This is particularly important in South Africa where clinical realities may be different from those in first world countries where many of the standard clinical models have originated. The present study contributes to the literature on the abuse of children in South Africa by documenting the precarious conditions under which many children and adolescents live in South African townships. It provides evidence for the value in the local South African clinical context of a treatment model for PTSD developed by in the United Kingdom (Ehlers \& Clark 2000; Clark \& Ehlers 2005), and shows how a therapist and client from different cultural backgrounds and languages were able to work together and achieve substantial therapeutic gains. However it also highlights how failures in the criminal justice system made the task of treatment more difficult. 


\section{Clinical setting in which Zanele received therapy}

Zanele came from an underprivileged background where resources and access to psychotherapy were limited. A social worker referred her to our research team in another town some $60 \mathrm{~km}$ distant. She was assessed and treated by the first author (CP) at a hospital internship site under the clinical supervision of the second author (DE). All interaction was in English which Zanele understood at a basic level. CP was careful not to use jargon and encouraged her to ask questions if she did not understand anything. Zanele regularly did indicate when she did not follow what was said, and communication seemed to work well on this basis. DE also provided research supervision as the case was to be written up as a Master's research report. Because this was part of a research project, considerable attention was given to following the treatment model carefully and funds were available to meet expenses which would not have been available for routine cases at the internship site.

\section{Research Methodology}

Case-based research methodology is an important complement to methods that use surveys or group comparisons (Edwards, Dattilio \& Bromley 2004). This is a systematic case study (Barker, Pistrang \& Elliott 2002) written according to the guidelines and principles described by Fishman (2005) as a basis for contributions to the online journal Pragmatic Case Studies in Psychotherapy. As a result the structure and headings are somewhat different from those of other research articles. Fishman provides a comprehensive framework for planning and reporting clinical case studies. The information obtained during the assessment and treatment was systematically organized into manageable units by means of three data reduction steps. First, the qualitative data from the assessment was summarized in an assessment report. This was used as the basis for a case formulation on which treatment planning was based. Second, the material from the therapy sessions was used as a basis for a case narrative in order to provide details of Zanele's progress through therapy. Third, the repeated measures on the quantitative selfreport scales were graphically displayed. All this material was interpreted using a series of reading questions (Edwards 2005b) that focused on the appropriateness of the interventions for
Zanele, the impact of interventions, processes of change in response to interventions and the effectiveness of treatment. This article is a shortened version of a fuller report (Payne 2006).

\section{Sources of data and quality control}

The following sources of information, collected during the course of assessment, therapy and follow-up, were drawn on at the data reduction stage.

1. Interviews: (1) A screening interview confirmed that the client met the criteria for PTSD. (2) Three assessment interviews furnished information on current presenting problems, developmental and family history. (3) A mid-treatment research interview, conducted by an independent clinical psychologist, explored Zanele's experience of therapy and whether there had been an alleviation of symptoms. (4) Three followup interviews in the sixth and seventh month after treatment termination included an assessment of current symptoms.

2. Session records: The 23 treatment sessions were audio-recorded. Soon after each session, the first author listened to each one in full and made detailed summaries. Particular attention was paid to aspects likely to be relevant for planning of interventions (guided by Ehlers and Clark's model) and material that needed clarification in the next session. Reliving sections of sessions were transcribed in full.

3. Self-report scales: Five self-report scales were administered to monitor Zanele's response to the intervention. The Beck Depression Inventory II (BDI-II) (Beck, Steer, \& Brown 1996) and the Beck Anxiety Inventory (BAI) (Beck \& Steer 1993) were administered on 21 occasions (during assessment and the majority of therapy sessions). These are 21-item measures of the clinical symptoms of depression and anxiety respectively. The Posttraumatic Stress Disorder Scale (PDS) (Foa, Cashman, Jaycox, \& Perry 1997) was administered during the assessment and 7 of the therapy sessions. It includes 17 items, which yield a symptom severity score. Two longer scales were administered twice, during the assessment and during therapy session 17: The 26 item version of the Posttraumatic Cognitions Inventory (PTCI) (Foa, Ehlers, Clark, Tolin, \& Orsillo 1999) which measure negative cognitions about the self, 
negative cognitions about the world and self-blame, and the 32 item Trauma-Related Guilt Inventory (TRGI) which measures dimensions of guilt associated with trauma (Kubany Haynes, Abueg, Manke, Brennan \& Stahura 1996). None of these tests appears in the list of Psychological Tests of the Health Professions Council of South Africa. However they are widely used in South Africa clinically and in research internationally. Xhosa translations of the Beck Inventories (Steele \& Edwards, 2008) were used and $\mathrm{CP}$ went through the other scales very carefully with Zanele to ensure she understood everything.

4. A copy was made of the therapy journal that Zanele kept after session 8 which she wrote in English.

5. Notes were made on the weekly supervision meetings between therapist and supervisor.

\section{Ethical aspects}

Ethical procedures of the Health Centre and University, pertaining to treatment and clinical research, were strictly adhered to. Zanele and her mother both signed an agreement form, giving informed consent for the sessions to be audio-recorded and for the case material to be used for research purposes and published as a case study. Pseudonyms have been used (except for the authors) and information has been omitted that might facilitate identification of the client and her family.

\section{BACKGROUND INFORMATION AND PSYCHOLOGICAL ASSESSMENT}

\section{Background information and how Zanele came to be in treatment}

Zanele, a 15-year-old black Xhosa-speaking female, from an Eastern Cape township, was in Grade 8 at high school. Her father had abused alcohol and marijuana and assaulted her mother on several occasions. After he suffered a stroke in 2002 and become disabled, his abusive behaviour escalated, and in 2004 his wife had divorced him and moved to another house in another street. Zanele was fond of her father, however, and continued to live in a simple and overcrowded house with her father, his mother, his brother and his brother's girlfriend and their children. In January 2006, Zanele and a friend were on their way home after visiting her friend's grandmother. A man whose name they did not know called them. They ignored him but he grabbed Zanele's arm. Her friend started to run away, and Zanele called out, asking her to call her uncle, but the man shouted at her, threatening to beat her if she told anyone. He forced Zanele into some bushes nearby and beat her face and arms. Then he pulled her pants off and began to rape her. A woman who walked by was afraid to intervene. When a man appeared, she screamed at him to call the police, but the perpetrator convinced him that there was no need as Zanele was his girlfriend. After raping her, he threatened to kill her if she told anyone about it.

The following month, Zanele saw the rapist in a shop. Terrified, she avoided making eye contact with him and left. He followed her out, grabbed her arm and forced her to go home with him. He then took a piece of wood and beat his girlfriend, who was pregnant, on the face and abdomen until her face was bleeding and she was crying. He then pushed her out the door, and told her to go home. Zanele feared for the unborn child and wondered what he would do to her if he could treat his own child in such a way. He locked the door and told her to pull her pants down. When she refused, he pulled them down, hit her face with his hands so that she was not able to see properly for some time and raped her. Afterwards she stood up and dressed herself, but he would not allow her to leave. He fell asleep and Zanele stood by the door crying, afraid he would rape her again when he awoke. At $3 \mathrm{~h} 45$ he woke up and told her to go home, threatening to kill her if she told anyone what had happened.

She told no one, partly because of the man's threats, and partly because she believed that her mother, who suffered from a heart condition, could not handle distressing information - she had had a minor heart attack and been hospitalized when she had learned about her husband's stroke four years previously. Zanele was worried that if her mother learned about the rapes she would be so shocked she would become ill and perhaps even die. By chance, however, the girlfriend of Zanele's uncle overheard someone saying they had heard that a man had beaten Zanele up. She questioned Zanele who told her about the rapes, and subsequently, and with some reluctance, she also told her mother and uncle. Her uncle accompanied her to the police station where she laid a charge. She was taken to a hospital in Port Elizabeth, where a medical examination and HIV test was done. She later reported the crimes to the school principal who referred 
Zanele to a social worker who, in turn, referred her to our clinical services.

\section{Summary of main problems and diagnosis}

On learning of the rapes, Zanele's grandmother became abusive, told her she was useless and beat her and Zanele felt she had no support from her family members. She found it difficult to communicate with others as many people in the area in which she lived had heard about what had happened to her. She felt isolated and alone, and feared for her life. Like many who have suffered similar traumas, she began to think negative thoughts which reinforced her sense of isolation: 'I will not be able to relate to people in the way that I used to,' 'people will not relate to me in the way they used to,' 'nowhere is safe,' 'men are dangerous,' my family are ashamed of me,' 'people who I thought would stand by me have let me down,' and 'I cannot rely on others.'

Zanele reported intense physiological distress when exposed to cues that resembled an aspect of the event. She regularly re-experienced the assaults and rapes through intrusive images and at times felt as if they were recurring. She attempted to avoid any conversations, activities and places, which reminded her of the traumas. At school, seeing a male teacher triggered such intense flashbacks that she saw him with the rapist's face and ran out of the classroom. Another flashback was of being hit on the head with a screwdriver and later, during therapy, she described nightmares in which she relived the events of the first rape. She was therefore afraid to fall asleep at night. In addition she reported increased autonomic arousal, which manifested in difficulties falling asleep, inability to concentrate and hypervigilance. Her score of 33.6 on the PDS fell within the moderate to severe range (severe $\geq 36$ ) and she met the DSM-IV criteria for chronic posttraumatic stress disorder. In line with this, her score of 50 on the BAI indicated severe anxiety symptoms.

She also reported having depressed mood for most of the day, nearly every day. She had lost interest in previously enjoyed activities, had low levels of energy and found it difficult to concentrate at school. Her initial score of 33 on the BDI-II fell within the severe range and she met the DSM-IV criteria for major depressive disorder (single episode).

\section{GUIDING CONCEPTION AND SUPPORTING RESEARCH}

Case formulation and treatment were based on the clinical model developed by Ehlers and Clark (2000: see also Clark \& Ehlers 2005; Ehlers, Clark, Hackmann, McManus \& Fennell 2005; Ehlers, Hackmann \& Michael 2004).

\section{Clinical theory on which formulation and treatment were based: Ehlers and Clark's Cognitive Therapy Model}

Most every day events are incorporated into autobiographical memory as a matter of course and become part of a person's identity and sense of themselves as a person with a continuous experience through time. Unusual and distressing events are less easy to incorporate because they do not fit existing schemas. However, if individuals reflect on them and discuss them with sympathetic friends or family, they are able to modify existing schemas to incorporate the new meanings implied by the new events. This is called 'elaborating the memory.' In the case of extreme traumatic events such as a rape or a severe accident, this process is even more difficult and, where individuals withdraw and do not disclose what happened, the trauma memory remains separate from autobiographical memory. Peritraumatic appraisals are the thoughts and interpretations individuals have during the trauma. These might include, for example, 'I am going to die,' or 'this is all my fault.' Parts of the memory associated with such appraisals are usually charged with intense emotion and are called 'hotspots.' Where trauma memories are not elaborated, such appraisals are not seen against the perspective of other experiences and retain a global and absolute quality. These split off memories fuel a sense of current threat, so that individuals feel chronically afraid, as if expecting another trauma to happen at any time. They are also likely to be triggered involuntarily by cues that are similar to stimuli associated with the trauma and to be experienced so vividly that individuals feel as if the trauma is happening again in the present.

Because PTSD symptoms are so intense and distressing, individuals also have thoughts about themselves and their future such as "I am going mad," or "I am weak and pathetic for not handling this well," or "I'll never be the same again, the trauma has ruined my life." These posttraumatic appraisals can lead to individuals 
trying to cope by suppressing the memories, avoiding triggering situations, and trying to focus on other aspects of their lives, or withdrawing from previously enjoyed social, recreational and work activities. However, this further interferes with the process of integrating the material into autobiographical memory. In this way attempts to cope maintain the conditions which give rise to PTSD symptoms.

\section{Clinical method on which treatment approach is based}

The three primary goals of treatment are to help clients to: (1) modify posttraumatic appraisals by providing psychoeducation about the nature of PTSD; (2) become aware of the process whereby cues trigger re-experiencing, and to recognize that triggering is different from the actual trauma; (3) discontinue the dysfunctional behaviours and cognitive strategies that are preventing elaboration of the trauma memory; (4) recover the trauma memory and elaborate it so as to identity and address negative perittraumatic appraisals and thus reduce reexperiencing, (5) re-engage with avoided activities and rebuild a life beyond the trauma. Each case is formulated individually based on an analysis of the client's triggers, trauma memory characteristics, appraisals, and cognitive and behavioural coping strategies that are maintaining the PTSD. A wide range of cognitive and behavioural techniques may be used in the process that might include: psychoeducation, Socratic questioning, cognitive restructuring, and behavioural experiments. Guided reliving of the trauma is particularly important for elaborating and restructuring the trauma memory (Grey, Young $\&$ Holmes 2002). Imagery techniques to replace images of traumatic memories are also used and Krakow, Hollifield, Johnston, Koss, Schrader et al's (2001) imagery rehearsal therapy was drawn on.

\section{Efficacy of Ehlers and Clark's Cognitive Therapy Model for PTSD}

Controlled trials have indicated that Ehlers and Clark's cognitive therapy is both an acceptable and effective treatment for PTSD. It is has been shown to be highly accepted by patients with substantial improvements occurring both during treatment and follow-ups (Clark \& Ehlers 2005). Ehlers, Clark, Hackmann, McManus, Fennell et al. (2003) offered motor vehicle accident survivors with persistent PTSD either cognitive therapy (CT), or repeated assessments (RA) or a self-help booklet (SH). CT was more effective at reducing the symptoms of PTSD and depression than SH and RA. At 9 months follow-up only 3 (11\%) CT patients had PTSD compared to with those who received SH (17 [61\%]), or RA (16 [55\%]). The effect size for the CT group (2.0) was significantly above that of the SH (close to 1.0) and RA $(<1.0)$.

Ehlers et al. (2005) further investigated the efficacy of cognitive therapy in treating 20 patients suffering from PTSD in a consecutive case series. At termination $90 \%$ of the patients no longer met the diagnosis of PTSD, which was maintained at a six-month follow up. The effect size of 2.8 is twice that typically reported in PTSD treatment studies. Following this, a randomized controlled trial was run in which CT was compared to a 3-month waitlist (WL) condition. Again, CT led to large reductions in symptoms of PTSD and depression. In the CT condition, $71 \%$ of participants no longer met criteria for PTSD, as compared to none in the WL group. Gains were maintained at a sixmonth follow up. The within group effect size was 2.82 on the PDS and 2.07 on the CAPS. Gillespie, Duffy, Hackmann and Clark (2002) trained trauma counsellors to use the CT model in the aftermath of the 1998 Omagh car bomb in Northern Ireland that killed 29 people and injured over 200 others. They reported a similar level of effectiveness in this applied setting to that found in the research trials. Finally, a trial of a similar treatment model adapted for children and adolescents was nearly complete when the present study was underway although it was only published a year later (Smith, Yule, Perrin, Tranah, Dalgleish \& Clark 2007). After treatment, $92 \%$ of participants no longer met criteria for PTSD as compared to $42 \%$ in a wait list control group and gains were maintained at six months follow-up. For CT the within group effect sizes were $3.43,3.71$ and 3.47 on three of the measures used, compared to $0.27,0.46$ and 1.59 for the WL group. Overall, therefore, there is considerable evidence that the Ehlers and Clark model of CT for PTSD offers an efficacious treatment.

\section{Clinical experience of therapist and supervisor relevant to the case}

The supervisor (DE) is a trained cognitive therapist, who, in order to thoroughly familiarize himself with the treatment model, had visited Ehlers and Clark's centre at the 
Institute of Psychiatry in London, attended some of their case supervision meetings and watched videos of several whole therapies from the research trials. The clinician (CP) had worked as a volunteer trauma counsellor for two years before training as a psychologist. During her Master's training she had done a basic course in cognitive therapy with the supervisor and this included attending weekly group supervision.

\section{CASE FORMULATION AND TREATMENT PLAN}

Zanele had had no opportunity to share what had happened to her with anyone and so had had no opportunity to review and elaborate the trauma memories. Although she had disclosed the rapes and her uncle had assisted in reporting the crimes to the police, there was no one to whom she could disclose the range of difficult thoughts and feelings associated with the rape and its aftermath. Her grandmother's abusive response had reinforced the belief that anyone who knew about the rapes would reject her. The flashbacks confused and terrified her and together with the depression made it difficult for her to focus on her school work. Although she had never spoken to a white person before, and was not very fluent in English, her meeting with the therapist (CP) clearly instilled some hope as her depression remitted quite rapidly during the assessment and her score of 13 (at each of assessment sessions 2 and 3) fell within the mild range.

She believed that her future had been destroyed by the rapes and that she would never be the same again. She suspected that she might have been infected with HIV but did not at this stage disclose this to the therapist who had been led to believe that she had been tested when she went to the hospital and found to be uninfected. Peritraumatic appraisals included an experience of extreme helplessness, the belief that the rapist would kill her and that she was partly responsible for what happened since she should have called for help during the second rape. The PTSD symptoms were caused by the failure to integrate the trauma memories and were being maintained by her coping by avoiding thinking or talking about what had happened and, as far as possible, avoiding triggering cues.

The treatment plan included psychoeducation about the nature of PTSD, training in discriminating and working with triggering cues, reliving and reprocessing the memories of the rapes in such a way as to stop the reexperiencing and empowering her to rebuild her life. Within this broad framework, detailed decisions about how to proceed were made by therapist and supervisor on a session by session basis. Interventions were implemented in a collaborative manner. A careful rationale was always given to Zanele and her willingness to engage with interventions was carefully checked.

\section{TREATMENT NARRATIVE}

\section{Treatment session 1: Working with triggers}

The flashbacks in which she saw the rapist's face superimposed on another male such as her teacher or uncle were particularly disabling and these were addressed first. Zanele was told that Raffi, a male nurse at the hospital, would sit across the room from her. When she was ready he would move half a metre closer to her. Zanele used a Subjective Units of Distress Scale (SUDS) to rate the degree of distress she was experiencing (1 indicated absence of distress and 10 indicated severe distress). After Raffi entered the office, she was asked to focus on his face and report back what she saw. She found it extremely hard to look directly at him. She became tearful, experienced some difficulty breathing, her heart beat fast and her hands were sweating. She saw the perpetrator's face and looked away. Her SUDS was 10. After a few minutes she focused on Raffi's face again. She was asked to describe how Raffi looked similar to or different from the perpetrator. She could recognize that Raffi had a darker complexion, was taller, and that his eyes, nose and mouth were different. She reported feeling more calm and said that Raffi could move closer. After about 20 minutes working with this, her SUDS had reduced to 5. Finally the therapist gave Zanele further psychoeducation about the nature of her anxiety responses and how they were being triggered. Zanele realised that despite the intense distress evoked she had been able to survive and learn new ways of coping.

\section{Treatment sessions 2-5: Safety and psychoeducation}

At session 2, Zanele reported a marked reduction in symptoms $(\mathrm{BDI}=9$; minimal; $\mathrm{BAI}$ $=8$ : mild; PDS = 11: normal). She had not had any flashbacks of the perpetrator's face, 
although she had some flashbacks of being physically assaulted. She was sleeping six hours a night and had gone to the mall something she had not done for some time. However, before the next session, the rapist was released on bail, and shortly afterwards the charges against him were dropped. In session 3, she became increasingly emotional as she remembered his threats that he would kill her if she told anyone about what he had done to her. The therapist focused on practical steps to ensure her safety including purchasing a self-defence pepper spray for her and planning that she not walk to school or to the shops alone and that she remain in well-lit areas after dark. It is not surprising that Zanele did not feel safe. A man who had twice raped her in broad daylight and who lived close to her father had been released back into the community and was completely free. At session 4 she reported that she was afraid to spend time at home alone and had accompanied her mother to work over the weekend. The flashbacks of the perpetrator's face had returned as had the nightmares, so she was sleeping only about 4 hours a night.

Afterwards, the therapist expressed her concerns about Zanele's safety to the social worker and investigating officer. The social worker helped Zanele apply for a protection order at the magistrate's court but was informed that this was not an option as the matter was not a "domestic dispute." In addition, the magistrate confirmed that the case had been dropped due to a lack of evidence as the events had occurred in January and February and the charges were laid in March. However, police officers accompanied her uncle to deliver a verbal warning to the perpetrator. Zanele asked her mother to accompany her to the police station to ascertain the status of the case. Again they were told the case had been dropped. However Zanele felt pleased when the investigating officer told her that the therapist had contacted him on three occasions. $\mathrm{He}$ indicated that he was trying to identify witnesses who could corroborate her story.

During these sessions the therapist focused on psychoeducation to help Zanele understand the distress she was experiencing. She played the game "Snakes and Ladders" (Kinchin \& Brown, 2001) with her and explained that recovery was like the game and she could expect to have ups and downs. She also suggested they repeat the triggering exercise with Raffi.

\section{TREATMENT SESSIONS 6-10: WORKING WITH TRIGGERS AND NIGHTMARES}

At session 6, Zanele's anxiety and depression were as severe as when she was first assessed and although her PTSD symptoms were slightly lower (see Figures 1, 2 and 3) she was now only sleeping for about two hours. This exacerbation of symptoms was precipitated by the rapist's brother who had approached and threatened her while she was at the mall. The therapist was concerned about whether Zanele could cope with the triggering exercise, but Zanele was keen to do it. After working for 40 minutes, her initial SUDS of 10 reduced to 4 . At the end, the therapist gave her the Snakes and Ladders game to take home. At the next session, Zanele's face lit up when she told how she had played the game with her mother who had told her that she was satisfied with her progress in therapy and encouraged her to continue. Zanele herself was realizing that she had a role to play in her own recovery and explained how she had been able to cope with a flashback of the perpetrator's face by reminding herself of what was happening and focussing on the differences between the person triggering the flashback and the actual perpetrator. After that there were no more of these flashbacks. She had told her uncle about the threats at the mall and he had again gone to the rapist's house with two policemen to warn him.

Now the most serious symptoms were the regular nightmares of being chased, caught and raped and the associated disruption of her sleep. During session 8 the therapist gave her a journal and encouraged her to write out the sequence of the nightmare in detail. She was then asked to change the ending in any way that she wished. She closed her eyes and used imagery to rehearse her new dream for ten minutes. Zanele enjoyed this aspect of the exercise and came up with many different endings. For example, she overpowered the perpetrator and ran away. She was encouraged to mentally rehearse a new dream ending for several minutes each day. At session 9 she reported that she had been doing this and that although she continued to have nightmares (roughly three times a week), the endings were different as she was either able to either defend herself or run away. Her therapy journal contained phrases such as: 'I am not responsible for what happened to me, but I am responsible for picking myself up', and 'you strike a woman, you strike a rock'. Session 10 
continued with work with imagery rehearsal. Because she had been able to handle the triggering exercise in sessions 1 and 6 and the imagery rehearsal, the therapist judged that Zanele could now cope with a guided reliving of the first rape and time was given to psychoeducation about this procedure.

\section{Sessions 11-17: Processing the trauma memory}

In session 11, Zanele was guided through the process of reliving the first rape. She was asked to describe it in the first person, in the present tense including as much detail as possible. She became extremely emotional, cried uncontrollably at times, and experienced difficulty breathing, sweating, rapid heart beat, and tightness in her stomach. However she was able to review the whole episode in detail. Prominent hotspots were at the points where she thought, "He's going to kill me," "He'll kill me if I scream," "I'm helpless" and "everyone will laugh at me if he throws my panties away." Two other hotspots where being hit on the head with a screwdriver and "feeling dirty and funny." In each case, the associated appraisals were challenged. For example, Zanele said 'I am scared that he is going to kill me'. Using the fast forward technique to the here and now, the therapist asked her what she knew now that she did not know then. She said she was still alive and realised that the fear she had of dying was a fear that was associated with the trauma memory, and that her life was not in immediate danger now. At the end, Zanele appeared much calmer and reported a SUDS level of 6 .

Following this session, although her anxiety was still high, Zanele no longer met criteria for PTSD (see figure 3). She had had no flashbacks since session 6 and now the nightmares had stopped and she was sleeping much better. In the next three sessions, Zanele and her therapist reviewed Zanele's experience of the reliving exercise and a narrative of the rape that she had written in her journal. She had also written that she was not ashamed about what had happened to her and she urged others who had been traumatized to speak out and wanted to help others who had had similar experiences. Zanele now disclosed another trauma not related to the rape. A week or so before the first rape, she and a friend had witnessed a hit and run accident in which a man was killed. As they were the only witnesses, the police had questioned them in a way which scared her as she experienced them as abrupt with her and acted as if she were lying. She had concluded that "policemen are scary" and this had been a factor in her not disclosing the rapes. Now she recognized that her family members had been supportive and that there were policemen too who were helpful and caring.

In session 14 the therapist also prepared Zanele for a reliving of the second rape which took place in session 15. During the reliving, she became extremely tearful and reported similar bodily sensations that she had felt during both traumas. The following hotspots were identified and rated with SUDS levels of 10: Being hit in the face, watching him beat his pregnant girlfriend on her stomach, being told to take off her pants, being locked in his house while he slept, fearing he would kill her when he awoke, wanting to call for help and not being able to, arriving home and worrying that she would be asked where she had been. Work was done on re-evaluating and restructuring each of these and at the end her SUDS level was 2. During the next two sessions, her experience of the therapy and her progress were reviewed carefully.

Meanwhile there had been little progress with the criminal case against the rapist. After session 15, the therapist contacted the police and was told that the investigating officer had moved to another town and that the case had been withdrawn by the prosecutor due to a lack of evidence. In session 16, Zanele reported that the perpetrator had raped another young girl (who was only six) and been taken into custody again. She felt secure knowing this, but a week later the therapist phoned the police again and was told that all charges had been dropped and the case closed.

\section{Sessions 18-23: HIV infection - a new crisis}

At this stage treatment seemed to be nearly over. But there was an unexpected development. In session 18, the therapist reviewed some of her responses to the PTCI. She indicated that being raped "had ruined her body/parts of her body." When this was explored further she became extremely emotional and cried uncontrollably. With great difficulty she disclosed that she had developed blisters around her genital area and that she had noticed a discharge. She was afraid that she had been infected with HIV. The therapist was taken by surprise. After all, once Zanele had 
disclosed the rapes she been seen at a hospital in Port Elizabeth and given an HIV test. She had been in the care of social workers who had referred her for therapy. Now, however, it became clear that the medical aspects had not been followed up and she had never received the result of the HIV test. The focus of the therapy switched to HIV education and pre-test counselling and the logistics of getting her tested. At school there had been a lesson on safe sex and she had nearly run out of the classroom her anxiety was so high. One option was for her mother to take her for testing, but she was unable to take time off work. Zanele was also afraid that if she was infected her mother would have another heart attack as she had done when her husband had had the stroke. The therapist arranged that she would accompany Zanele to a nearby clinic for a medical examination during session 20. At Zanele's request the therapist went into the consulting room with her and supported her while she had blood taken, a procedure she found frightening. Zanele cried through much of the consultation. The doctor confirmed she had gonorrhoea and that the other results would be available the following week. Back at the therapist's office Zanele shared her fears. Despite her distress she realized that even if infected her life would not be over. Her mother had told her not to worry but this had angered her as she could see that this was a way of avoiding facing reality.

A few days later the therapist was informed that Zanele was infected with HIV, chlamydia and syphilis. She prepared herself to break this news to her at the next session (21). On hearing her results, Zanele's eyes widened and she broke down and sobbed uncontrollably. There was a focus on supporting her and clarifying the different feelings and thoughts she had as she tried to take in the implications of this. Zanele asked her to meet with both her mother and herself later on during the week to disclose her status to her mother and the therapist made arrangements for the social worker to ensure she received proper medical treatment in her home town.

During session 22, the therapist shared the results with Zanele's mother, as Zanele looked on to see how her mother would respond. Zanele sobbed as her mother repeatedly whispered, 'Sukulile... yomelela' (Be strong, don't cry). Through her tears Zanele managed to say 'Mama, I have HIV'. This was a poignant moment as her mother fought back her own tears. Zanele asked for her mother's support during this difficult time. The session ended with Zanele and her mother agreeing only to disclose this information to Zanele's sister. During session 23, Zanele reported that she had had a good experience at the clinic that was providing treatment for the STD's she had been infected with and that, on reading the educational booklet on HIV she had been given, she realized that she still had a future, just a different one to the one she had planned. She was considering going back to the police station and informing them of her HIV status, in the hope that the case would be re-opened.

\section{Progress of the criminal case against the rapist and follow-up with Zanele}

By now Zanele no longer suffered from PTSD and depression and she had navigated the painful process of facing her medical status with courage and common-sense. However, the rapist was still at large and all charges had been dropped. There were further sessions with Zanele until the end of the year when the therapist completed her internship. These focused on building social support, living with HIV and her plans for the future.

In May the following year, the authors presented the case at the annual conference of the South African Professional Society on the Abuse of Children (SAPSAC) (Payne \& Edwards 2007). A senior advocate who heard it offered to have the criminal case looked into. The therapist met with Zanele and her mother and established that they strongly supported this. In July the case was formally re-opened. The therapist met with Zanele in mid June and early July and was able to conduct a thorough clinical assessment. Despite the impending court case, she was coping well. There was no evidence of a return of PTSD symptoms and on both occasions her scores of 3 on the BDI-II and 2 on the BAI indicated normal levels of symptoms of anxiety and depression.

\section{MONITORING: GRAPHICAL PRESENTATION OF REPEATED MEASURES}

Scores on the BDI-II, BAI and PDS are displayed in Figures 1-3 respectively. The high scores on all measures are consistent with how Zanele presented and the diagnoses of PTSD and MDD. However the marked drop in all scores after the first assessment session shows that her meeting with the therapist had 
considerable impact. One factor responsible for this is that she had begun to share her story in detail for the first time, and thus felt less alienated and alone. She later told the therapist that psychoeducation about PTSD and the normalisation of her symptoms was especially important, as she realised that what she was experiencing did not mean she was 'going crazy'.

During the early phase of treatment she was realizing that her symptoms could be tackled as she experienced the impact of the work with triggering. At the same time she was having to deal with the release of the perpetrator, the dropping of the case and intimidation by the perpetrator's brother. The peaking of scores at session 6 reflected the lack of safety she felt after being threatened in the mall, coupled with the fact that the trauma memories had not yet been dealt with therapeutically. The steady decline in her depression that followed is probably related to her finding meaningful support from her family, her sense of taking charge of her life and the recognition that she could tackle painful experiences as her depressive symptoms had mostly dissipated even before the first reliving in session 11 . Her PTSD symptoms also declined steadily but the most important shift happened after the first reliving in session 11 which was followed by a cessation of the nightmares. Her anxiety as measured by the BAI also declined, bur more slowly. Two factors may have contributed to this: her fear of seeing a dead body (which was only disclosed in session 13) and her fear of HIV infection (although her BAI had dropped considerably by the time this was tackled in session 18).

\section{DISCUSSION AND CONCLUSIONS}

By the time Zanele was assessed by us, she had developed chronic PTSD and depression and it seems improbable that the rapid gains she made can be attributed to spontaneous remission (Barker et al. 2002). There is evidence that it was the psychoeducation and normalizing of symptoms that contributed to the rapid reduction of symptoms initially. This is widely recognized as a significant component of early intervention (Hamblen 1998). Factors that contributed to further progress were her experience of support from the therapist and her family, her experience in therapy of tackling symptoms head on with the triggering intervention, and her working with the trauma narrative through writing and reliving so that she was able to integrate the rapes into autobiographical memory and not be trapped in overgeneralizations from these two experiences such as "all men can hurt me" or "nowhere is safe". Therapists sometimes shrink back from a reliving intervention because they are concerned that it might retraumatize clients. However, this study provides evidence that, when appropriately timed and carefully managed, it can have a marked impact on reexperiencing symptoms. The same was found in the case of Langu whose PTSD was precipitated by a motor vehicle accident in which his brother died (Karpelowsky \& Edwards 2005).

This study also reminds us that being infected with HIV as a result of being raped constitutes a second trauma (see also Davidow \& Edwards 2007). Zanele avoided discussing her fears about this with the therapist and nearly ran out of the classroom during a class on safe sex practices. However, by the time she came to face the medical consequences and her HIV infection with the therapist she had largely processed the trauma of the rapes themselves. She seemed to have found a natural resilience (Yehuda, Flory, Southwick \& Charney, 2006) and capacity to cope with tough life circumstances and did not develop clinical levels of symptoms again.

The qualitative data from the sessions, together with the quantitative scores on the BDI BAI, and PDS and the interview data and BDI and BAI scores at follow up six months after the formal termination of this treatment provide evidence that the complete remission of clinical symptoms that took place over the course of the therapy was well maintained. It seems unlikely that she would have progressed to that state without the therapy interventions since by then she was anticipating involvement in the trial of the rapist.

The narrative provides evidence for the transportability of the treatment model of Ehlers and Clark (2000) which was the basis on which therapist and supervisor made treatment decisions. The model was developed for adults in the UK, although a trial of an adaptation for children and adolescents was underway and has since been published (Smith et al. 2007). An important feature of the model is that it is formulation-driven. This means that the clinician selects interventions based on a comprehensive understanding of the case. It 
proved to be very adaptable for the work with Zanele who engaged with each aspect of the therapy process and built on it at home between sessions. Thus the snakes and ladders game (Kinchin \& Brown, 2001) was comfortably accommodated within the therapy plan, and for other cases, other play and expressive techniques could also be incorporated (Edwards 2009). Prominent features of the model that were helpful were: psychoeducation and normalizing of symptoms, work with discrimination of triggers, elaborating the trauma memory through retelling, journaling and reliving in a way that allowed reality testing and separation of then (the trauma events) and now, and work on empowerment and reclaiming her life.

This kind of case study offers an in-depth view into an episode in the life of a young South African rape survivor and into her everyday experiences. A narrative such as this portrays her unfolding experience in a way that can speak directly to other trauma survivors and those that work to support them (Karpelowsky \& Edwards 2005). Sadly we know that such experiences are all too common especially among those living in economically deprived conditions. Edwards (2005a) has reviewed South African studies that enumerate the number of children and adolescents who are raped or who suffer from symptoms of depression and PTSD. These tell us an important part of the story, but clinical case studies complement these bald figures by documenting the psychological dimensions of a survivor's experience and of the journey towards recovery. Because of the depth of the therapeutic process they offer information about psychological processes that might not be accessible in a non-clinical interview.

It is often said that one cannot generalize from case studies. That is true in so far as no other rape survivor's experiences will be the same as those of Zanele's. However it is false and misleading in that elements of Zanele's experience are likely to be found again and again among rape survivors - the confusion, alienation, and fear evoked by the intense psychological symptoms, the shame about what has happened, and the despair about rebuilding one's life. Similarly Zanele's story tells us that despite the horror and brutality of events to which many young people in South Africa are exposed, the components of Zanele's path to recovery can be repeated again and again if rape survivors get the right kind of help.

Zanele's story also points to the importance of different role-players playing their part in the recovery process. Despite having been raped and sent to hospital, Zanele received inadequate medical care. The social worker played a valuable role in referring her for treatment and in supporting Zanele in maintaining her therapy. However, on one occasion the social worker indicated that each client is only supposed to have three consultations and in this case Zanele received much more than this. Despite this, the social worker had not followed up the medical aspects and was able to do little to use the justice system to support Zanele. Finally the justice system itself was found to be sorely wanting. A rapist infected with a host of sexually transmitted diseases including HIV was able to rape Zanele twice and then rape a six-year-old child and the local prosecutors were unable to bring a case against him. Apart from the sad commentary this offers on the state of these services in South Africa, it means that it can be hard for therapists to establish safety for the clients with whom they work. Yet establishing safety is the first step in treating PTSD and the absence of such safety interferes with treatment. Despite this, the police did play a role in warning the perpetrator not to harass Zanele further although this did not prevent him raping another girl. While psychologists may need to play diverse roles in the context of deprived communities with limited resources, it is clearly a waste of their training if they have to devote time to following up aspects of a case that would better be dealt with by other professionals and there is a danger that a community psychologist becomes a "jack of all trades and master of none." Treatment of PTSD is a specialist process and although it can sometimes be completed in a few sessions, it often takes longer. Zanele's therapy was prolonged by the setbacks caused by the perpetrator's release into the community and the need to address her medical infections (although this was only done once the PTSD and depression were resolved). 
Figure 1: Zanele's BDI scores

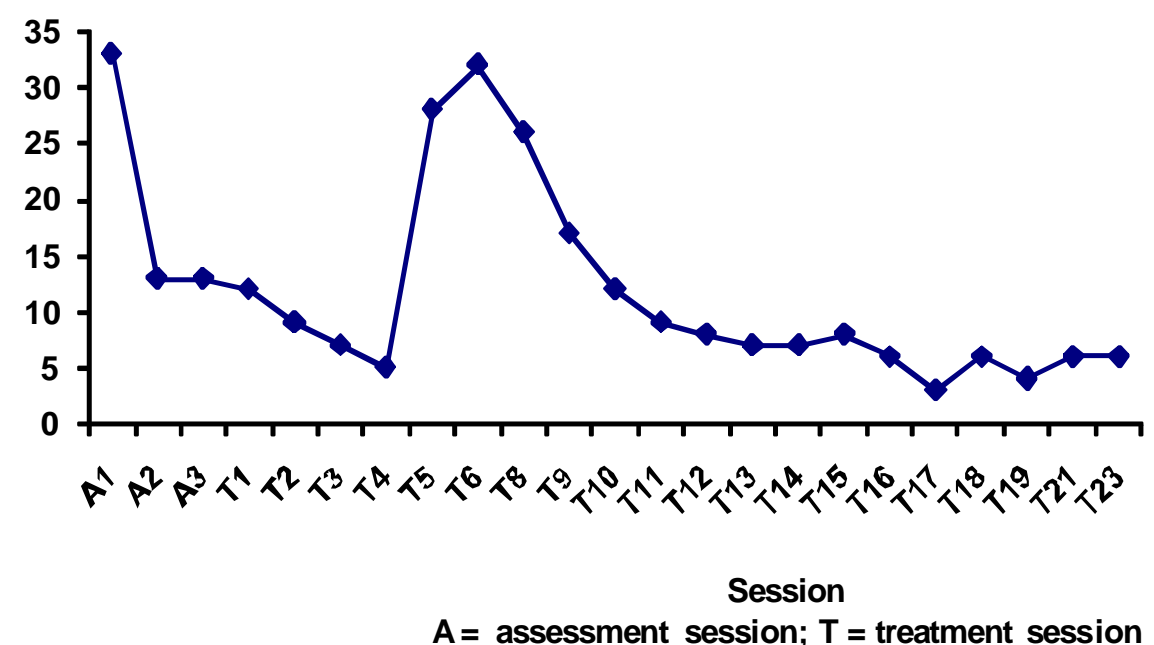

Figure 2: Zanele's BAI scores

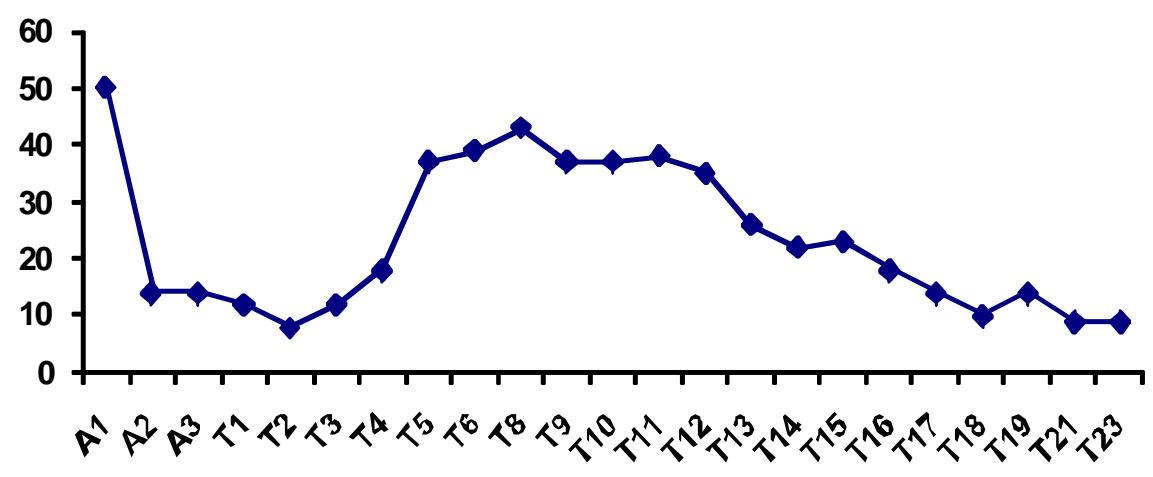

Sessions

A = assessment session; $T=$ treatment session

Figure 3: Zanele's PDS scores

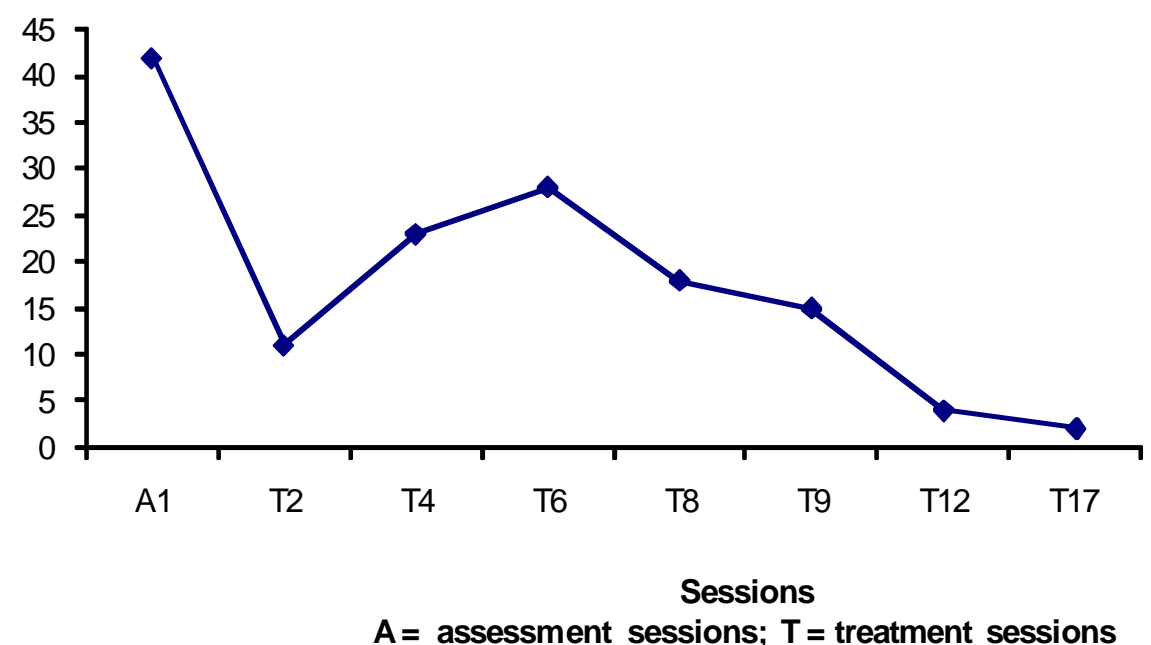




\section{REFERENCES}

Barker, C, Pistrang, N, \& Elliott, R. 2002. Research methods in clinical psychology: An introduction for students and practitioners. 2nd edition, John Wiley: Chichester.

Beck, AT \& Steer, RA. 1993. Beck Anxiety Inventory: Manual. Psychological Corporation, San Antonio TX.

Beck, AT, Steer, RA. \& Brown, GK. 1996. Beck Depression Inventory Second Edition: Manual Psychological Corporation, San Antonio TX.

Clark, DM \& Ehlers, A. 2005. Posttraumatic stress disorder: From cognitive theory to therapy, in Contemporary cognitive therapy, RL Leahy, ed. Guilford, New York:141-160.

Davidow, A \& Edwards, DJA. 2007. Treatment of PTSD and depression in a black South African rape survivor: A case based evaluation of Ehlers and Clark's clinical model, Paper presented at the World Congress of Behavioural and Cognitive Therapies: Barcelona, Spain (July).

Edwards, DJA. 2005a. Post-traumatic stress disorder as a public health concern in South Africa. Journal of Psychology in Africa 15(2):125-134.

Edwards, DJA. 2005b. Treating PTSD in South African contexts: A theoretical framework and model for the development of evidence-based practice, Journal of Psychology in Africa 15(2):209-220.

Edwards, DJA. 2009. Treating posttraumatic stress disorder in South Africa: An integrative model grounded in case-based research. Journal of Psychology in Africa, accepted for publication.

Edwards, DJA, Dattilio, F \& Bromley, DB. 2004. Developing evidence-based practice: The role of case-based research. Professional Psychology: Research and Practice 35(6):589-597.

Ehlers, A \& Clark, DM. 2000. A cognitive model of posttraumatic stress disorder. Behaviour Research and Therapy 38:319-345.

Ehlers, A, Clark, DM, Hackmann, A, McManus, F \& Fennell, M. 2005. Cognitive therapy for posttraumatic stress disorder: development and evaluation. Behaviour Research and Therapy 43(4):413-431.

Ehlers, A, Clark, DM, Hackmann, A, McManus, F, Fennell, M, Herbert, C \& Mayou, RA. 2003, A randomized controlled trial of cognitive therapy, a self-help booklet, and repeated assessments as early interventions for posttraumatic stress disorder. Archives of General Psychiatry 60(10):10241032.

Ehlers, A, Hackmann, A \& Michael, T. 2004. Intrusive re-experiencing in posttraumatic stress disorder: Phenomenology, theory and therapy. Memory 12(4):403-415.

Fishman, DB. 2005. Editor's Introduction to PCSP From Single case to database: A new method for enhancing psychotherapy practice, Pragmatic Case Studies in Psychotherapy [Online], 1: Module 1, Article 2. Available: http://pcsp.libraries.rutgers.edu.

Foa, EB, Cashman, L, Jaycox, L \& Perry, K. 1997. The validation of a self-report measure of a posttraumatic stress disorder: The post traumatic diagnostic scale. Psychological Assessment 9(4): 445451.

Foa, EB, Ehlers, A, Clark, DM, Tolin, DF \& Orsillo, SM. 1999. The posttraumatic cognitions inventory (PTCI): Development and validation. Psychological Assessment 11(3):303-314.

Foa, EB \& Rothbaum, BO. 1998, Treating the trauma of rape: Cognitive-behavioral therapy for PTSD. Guilford, New York.

Gillespie, K, Duffy, M, Hackmann, A \& Clark, DM. 2002. Community based cognitive therapy in the treatment of post-traumatic stress disorder following the Omagh bomb. Behaviour Research and Therapy 40:345-357.

Grey, N, Young, K \& Holmes, E. 2002. Cognitive restructuring within reliving a treatment for peritraumatic emotional 'hotspots' in posttraumatic stress disorder. Behavioural and Cognitive Psychotherapy 30(1): 37-56.

Hamblen, J. 1998. PTSD in children and adolescents: A National Center for PTSD fact sheet. Downloaded on May 28, 2009 from http://www.tema.ca/lib/PTSD\%20in\%20Children\%20and\%20Adolescents.PDF

Jewkes, R \& Abrahams, N. 2002. The epidemiology of rape and sexual coercion in South Africa: An overview. Social Science and Medicine 55:1231-1244.

Karpelowsky, BJ \& Edwards, DJA. 2005. Trauma, imagery and the therapeutic relationship: Langu's story. Journal of Psychology in Africa 15(2):185-195. 
Kinchin, D \& Brown E. (2001). Supporting children with post-traumatic stress disorder: A practical guide for teachers and professionals. London: David Fulton.

Krakow, B, Hollifield, M, Johnston, L, Koss, MP, Schrader, R, Warner, TD, Tandberg, D, Lauriello, J, McBride, H, Cutchen, L, Cheng, D, Emmons, S, Gemain, A, Dominic-Melenderez, P-T, Sandoval, D, \& Prince, H. 2001. Imagery rehearsal therapy for chronic nightmares in sexual assault survivors with PTSD: A randomised controlled trial. JAMA: The Journal of the American Medical Association 286(5):537-545.

Kubany, ES, Haynes, SM, Abueg, FR, Manke, FP, Brennan, JM \& Stahura, C. 1996. Development and validation of the trauma-related guilt inventory (TRGI). Psychological Assessment 8(4): 428-444.

Payne, C \& Edwards, DJA. 2007. Breaking the silence of child rape. Paper presented at the 8th national conference of the South African Professional Society on the Abuse of Children, Pretoria (May).

Payne, C. 2006. Breaking the silence: Zanele's journey of recovery. Unpublished research report for Master's in Clinical Psychology. Grahamstown: Rhodes University.

Smith, P, Yule, W, Perrin, S, Tranah, T, Dalgleish, T, \& Clark, DM. 2007. Cognitive-behavioral therapy for PTSD in children and adolescents: A preliminary randomized controlled trial. Journal of the American Academy of Child and Adolescent Psychiatry. 46(8):1051-1061.

South African Police Service. 2005. Crime Information Analysis Centre Statistics for 2004/5.

Downloaded 25 March 2009 from http://www.saps.gov.za/statistics/reports/crimestats/2005/categories.htm

Steele, G \& Edwards, DJA. 2008. Development and Validation of the Xhosa Translations of the Beck Inventories: 2. Item analysis, internal consistency and factor analysis. Journal of Psychology in Africa 18:217-226.

Yehuda, R, Flory, JD, Southwick, S \& Charney, DS. 2006. Developing an agenda for translational studies of resilience and vulnerability following trauma exposure. Annals of the New York Academy of Sciences 1071:379-96. 